Case report

\title{
Prolongation of survival time and improvement of the quality of life after treatment with liposomal irinotecan in the patient with metastatic pancreatic adenocarcinoma
}

\author{
Wojciech Rogowski ${ }^{1,2}$, Przemysław Będkowski ${ }^{1,3}$ \\ ${ }^{1}$ Department of Clinical Oncology, Chemotherapy, Clinical Research, Provincial Specialist \\ Hospital in Slupsk \\ ${ }^{2}$ Pomeranian Academy in Slupsk \\ ${ }^{3}$ Department of Daily Chemotherapy, Provincial Hospital in Koszalin
}

Correspondence:

Wojciech Rogowski Department of Clinical Oncology, Chemotherapy, Clinical Research, Provincial Specialist Hospital in Slupsk 76-200 Słupsk, ul. Hubalczyków 1

Received: 13.03.2021 Accepted: 15.07.2021

DOI: 10.24292/01.OR.123150721 Copyright $\odot$ Medical Education. All rights reserved.

\section{ABSTRACT}

Pancreatic cancer is one of the malignant neoplasms with the worst prognosis. It is most often diagnosed at an advanced stage, which relates to unsatisfactory results of the therapy. Only about $15-20 \%$ of patients with pancreatic cancer qualify for surgery. The remaining patients are diagnosed with locally advanced disease or much more frequently in the generalized stage. Systemic treatment (chemotherapy) remains the mainstay of therapy in these patients, but both the response rate and progression-free time are unsatisfactory [1, 2].

This paper presents a case of a patient with metastatic pancreatic cancer, in whom three lines of systemic treatment were applied sequentially, which allowed to extend the survival time and improve the quality of life.

Key words: pancreatic cancer, chemotherapy, gemcitabine, liposomal irinotecan 


\section{INTRODUCTION}

Pancreatic cancer is a relatively rare malignant neoplasm, it is responsible for approx. $2 \%$ of all neoplasms. Nevertheless, due to the very high mortality rate, today it is the fourth most frequent cause of death, both among women (after lung, breast and colon cancer) and men (after lung, prostate and colon cancer) [3]. Late diagnosis of the disease and the resulting poor prognosis are a consequence of the lack of early pathognomonic symptoms. The 5 -year survival rate does not exceed $10 \%$ in both sexes. The significant progress made in the diagnosis and therapy of cancer does not translate significantly into the results of pancreatic cancer treatment.

The inoperable nature of the described neoplasm in most patients means that chemotherapy remains their only chance. The character of the therapy is palliative. There has been no spectacular success in the treatment of pancreatic cancer in recent years. Nevertheless, as new cytostatics active in this tumor were registered, it turned out that in some patients, after I line treatment failure, another attempt could be made, thanks to which it is possible to further extend the survival time and improve the quality of life [4].

It has been shown that in the case of disease progression after I line chemotherapy, another-line treatment may be considered in approximately $40-50 \%$ of patients. Patients undergoing I line chemotherapy according to the FOLFIRINOX regimen, in II line chemotherapy can be treated with gemcitabine as monotherapy or in combination with nab-paclitaxel [5].

In turn, patients treated in the I line with chemotherapy with gemcitabine can be offered 5-fluorouracil derivatives along with platinum derivatives in the II line. The latest registration of another active substance in advanced pancreatic cancer was made thanks to the NAPOLI-1 study, which concerned irinotecan liposomal. This drug showed a clinical benefit in terms of overall survival as well as progression-free time [6].

\section{CASE REPORT}

A 36-year-old patient with no comorbidities was diagnosed and treated by general practitioner (GP) care for abdominal pain that had lasted for several weeks. Due to the ailments, gastroscopy was performed and the result was normal. Regardless of the results of the research, therapy with a proton pump inhibitor (PPI) was initiated, but no effects. The loss of body weight that appeared in the next stage was the reason for performing ultrasound (USG) of the abdominal cavity. The result was also undiag- nostic, the examination performed by the pediatrician at the GP did not show any abnormalities. The lack of effect of the therapy and the increasing symptoms prompted the doctors to conduct another ultrasound examination. This time, the radiologist performed them on different equipment. The study showed a heterogeneous picture of the pancreas with a suspected hypoechoic area within the tail of the pancreas. Hypodensive lesions in the liver were also found. As a consequence, the computed tomography (CT) of the abdomen and pelvis was performed. The study revealed a lack of contrast indicating pulmonary embolism in the arteries to segments IX and X of the right lung, and a focus of $8 \mathrm{~mm}$ parenchyma densities in segments I and II, which may correspond to a consolidating nodule. The pleural cavities were free. The changes were considered to be clinically insignificant. Within the abdominal cavity and pelvis, numerous metastatic lesions up to $51 \times 39 \mathrm{~mm}$ were found in segments $\mathrm{VI}$ and $\mathrm{VII}$ of the liver. The pancreas showed heterogeneous, weaker post-contrast enhancement with emerging hypodense areas in the body and tail. The tail of the pancreas showed an obliterated upper dorsal outline with thickened adipose tissue. In the abdominal cavity, enlarged lymph nodes $17 \times 12 \mathrm{~mm}$ in size and with blurred outlines were also found. A decision was made to perform a core needle biopsy of the liver. The result indicated pancreatic adenocarcinoma. On August $30^{\text {th }}, 2019$, systemic treatment was introduced according to the FOLFIRINOX scheme. The patient still complained of abdominal pain, which, however, did not limit his activity. The performance level at the start of therapy was assessed as ECOG 0.

Chemotherapy was administered from the beginning in the cover of growth factors. Neutropenia was avoided. Treatment tolerance was assessed as good. After 2 months of therapy, the control CT scan of the abdominal cavity showed stabilization of the disease. A slight enlargement of changes in the liver was observed, but it did not meet the progression characteristics according to RECIST (Response Evaluation Criteria in Solid Tumors). After another month, abdominal pain worsened. They were accompanied by tenderness of the abdominal wall found on physical examination. Laboratory tests have shown an increase in the activity of transaminases.

A CT scan was performed which showed progression according to the RECIST criteria. A decision was made to continue chemotherapy according to the PG regimen (cisplatin, gemcitabine). Treatment was continued for 4 months until the next radiological progression. At the same time, DNA sequencing was commissioned from the Roche Foundation to find potential biomarkers to guide the next line of therapy. The results of molecular tests did not show any predictive factors that would allow the use of 
personalized treatment. The patient was performance status was assessed at WHO 1. Due to the disease progression, the patient was qualified to receive next-line chemotherapy according to the FOLFIRI regimen based on irinotecan liposomal. The treatment began on May $15^{\text {th }}, 2020$. It was decided to additionally monitor the course of the disease using the Ca 19-9 marker. Its baseline level before the start of III-line therapy was $6537 \mathrm{U} / \mathrm{ml}$ (normal $<37 \mathrm{U} / \mathrm{ml}$ ). After five treatment cycles, a follow-up CT scan of the abdominal cavity and pelvis was performed. It showed a slight reduction in changes in the liver and pancreas, however, the disease stabilized on the RECIST scale. Until this stage of therapy, it was very well tolerated, the efficiency level at the time of the first radiological assessment was still WHO 0 . In laboratory tests, a decrease in CA 19-9 marker to $3950 \mathrm{U} / \mathrm{ml}$ was observed. Due to the positive therapeutic effect and good tolerance, treatment with the FOLFIRI regimen was continued, with its monitoring planned every 2 months, assuming no clinical symptoms of disease progression. Another follow-up CT scan (October 2020) showed sustained stabilization according to RECIST criteria.

The downward trend of the Ca 19-9 marker stopped. The therapy was continued. In its further course, the following side effects were observed: CTC-2 diarrhea, which increases with the duration of treatment, and G1 weakness. Abdominal pain persisted along with tenderness in the mesogastrium and epigastric region. At the patient's request, taking into account the palliative nature of chemotherapy, some intervals between chemotherapy cycles were extended to 3 weeks. Until now, the patients has been receiving liposomal irinotecan, which means that he has been treated for 19 months.

\section{DISCUSSION AND CONCLUSION}

The presented case report shows that there is a subpopulation of patients with advanced pancreatic cancer with distant metastases for whom survival can be significantly prolonged. The key to success is the use of cytostatic drugs in sequential therapy: three lines of treatment were successfully performed in the described patient. Irinotecan liposomal, approved for the treatment of pancreatic cancer after gemcitabine failure, proved to be effective in the III line. If the pancreatic cancer in patient with good status of performance progresses, the next line of treatment should always be considered.

\title{
References
}

1. Vincent A, Herman J, Schulick R et al. Pancreatic cancer. Lancet. 2011; 378(9791): 607-20.

2. McGuigan A, Kelly P, Turkington RC et al. Pancreatic cancer: A review of clinical diagnosis, epidemiology, treatment and outcomes. World J Gastroenterol. 2018; 24(43): 4846-61. http://doi.org/10.3748/wjg.v24.i43.4846.

3. Wojciechowska U, Didkowska J. Zachorowania i zgony na nowotwory złośliwe w Polsce. Krajowy Rejestr Nowotworów, Narodowy Instytut Onkologii im. Marii Skłodowskiej-Curie - Państwowy Instytut Badawczy. http://onkologia.org.pl/raporty (access: 1.03.2021).

4. Martín AM, Hidalgo M, Alvarez R et al. From First Line to Sequential Treatment in the Management of Metastatic Pancreatic Cancer. J Cancer. 2018; 9(11): 1978-88. http://doi.org/10.7150/jca.23716.

5. Von Hoff DD, Ervin T, Arena FP et al. Increased survival in pancreatic cancer with nab-paclitaxel plus gemcitabine. N Engl J Med. 2013; 369: 1691-703.

6. Wang-Gillam A, Hubner RA, Siveke JT et al. NAPOLI-1 phase 3 study of liposomal irinotecan in metastatic pancreatic cancer: Final overall survival analysis and characteristics of long-term survivors. Eur J Cancer. 2019; 108: 78-87.

\author{
Authors' contributions: \\ All authors contributed equally to the article. \\ Conflict of interests: \\ The authors declare no conflict of interest regarding the publication of this article \\ Financial support: \\ None. \\ Ethics: \\ The authors had full access to the data and take full responsibility for its integrity. \\ All authors have read and agreed with the content of the manuscript as written. \\ The paper complies with the Helsinki Declaration, EU Directives and harmonized requirements for biomedical journals.
}

